\title{
Improving the lifetime of an electro-compressor for autoclave with optimized buffer tank
}

\author{
Iulian Vlăducă ${ }^{1, *}$, Claudia Irina Borzea $^{1}$, Carmen Gheorghiţa Petre $^{1}$, Romeo Dorin Hriţcu ${ }^{1}$, \\ Raluca Lucia Maier ${ }^{1}$, Vicențiu Liviu Ringheanu ${ }^{1}$, and Ramona Manuela Stanciuc ${ }^{1}$ \\ ${ }^{1}$ Romanian Research and Development Institute for Gas Turbines COMOTI, 061126 Bucharest
}

\begin{abstract}
In order to increase the research capabilities in the field of lowweight intelligent materials and high structural performance, and also to increase energy efficiency, a study was conducted on improving the operating time of a hot air autoclave compressor with a buffer tank. The booster screw electro-compressor of $200 \mathrm{~kW}$ is designed to compress technological air to the installation's necessary parameters at $1 \mathrm{ppm}$ air purity, and the pressurized buffer tank is designed to reduce the number of start-ups of the compressor unit and its motor, in order to increase its lifespan. The pressure can vary in the designed buffer tank from 7 to 26 bar (abs). The autoclave parameters record thermodynamic modifications as it heats up to $400{ }^{\circ} \mathrm{C}$ at the working pressure. Cool air is required during the cooling process. The air mass exchanged during operation for cooling down to atmospheric temperature was calculated. The data obtained was used for validating an optimally designed buffer tank within the required operational parameters limits, set and acquired by the custom-made automation system.
\end{abstract}

\section{Introduction}

An autoclave is basically a heating equipment combining an oven and a pressure chamber. Using an autoclave enables a good control of the pressure and temperature [1], and is used for curing. Autoclave moulding is widely used in the aerospace industry [2], for manufacturing composites of high quality $[3,4]$, based on prepregs.

The pre-impregnated laminae are laid onto the tool surface, on top of which a peel ply, bleeder ply and vacuum bag are placed. The entire assembly, once sealed, is placed in the autoclave. Vacuum operation has the role of removing the voids in the composite materials, thus consolidating the ply while volatiles that may form during the moulding process are continuously removed in order to reduce the incidence of porosity. Voids can cause structural damage which may significantly affect the structural integrity and remaining useful lifetime of the aircraft [3]. By combining vacuum and pressure applied on the assembly, a uniform pressure is results on the part surface. Thus, the autoclave process is able to provide very high-quality laminate composites in terms of material uniformity, dimensional tolerances. This technology, however, can be prohibitively expensive unless

* Corresponding author: iulian.vladuca@,comoti.ro 
the level of quality control and very narrow tolerances are imperatively imposed in the manufacturing field.

The autoclave discussed is used for the polymerization of composite materials for aerospace components [2]. The aim is to prolong the lifetime of the induction motor and its driven compressor by choosing the right installation parameters and buffer tank. The parameters are acquired by a specially designed automation control system with PLC and Panel PC distributed local data acquisition. The autoclave (Figure 1) was installed together with a compressor assembly and an air dryer.

a)

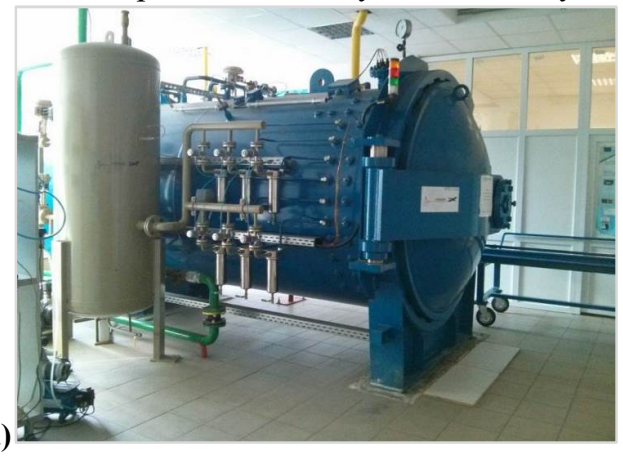

b)

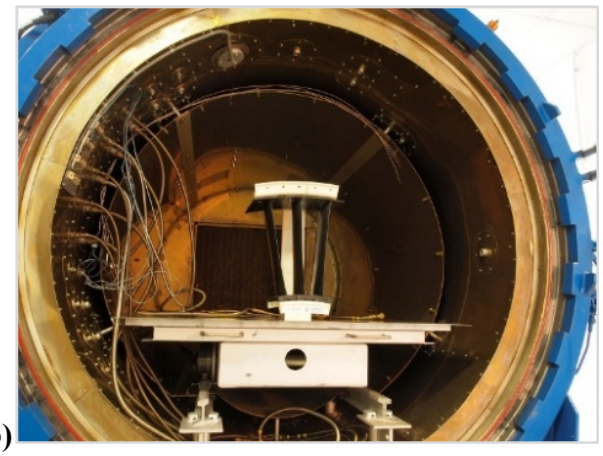

Fig. 1. a) Scholz autoclave, b) Interior with carbon fibre aerofoil

\section{Twin-screw electro-compressor used}

For the given application, a CU 128 [5] compressor unit [6] was chosen, having the characteristics in Figure 2. This one is driven by a $200 \mathrm{~kW}$ asynchronous motor. The minimum and maximum pressures of the CU64, CU90 and CU128 compressor units are constant, being: min. 6 bar (abs) and maximum 26 bar (abs). The characteristics are relatively similar, differing in the power consumed and circulated gas flow, depending on their construction size. The air inlet temperature range is $-40{ }^{\circ} \mathrm{C} \div 50{ }^{\circ} \mathrm{C}$. The compressor operating requirements of the autoclave installation are: working fluid: air; air flow: 780 $\mathrm{Nm}^{3} / \mathrm{h}$; suction pressure: 1 bar (atmospheric pressure); suction temperature: $-20{ }^{\circ} \mathrm{C} \ldots+40$ ${ }^{\circ} \mathrm{C}$; discharge pressure: max. 20 bar; discharge gas temperature at autoclave inlet: $50{ }^{\circ} \mathrm{C}$; residual oil content: $0.01 \mathrm{ppm}$; remanent particles: max. $1 \mu \mathrm{m}$.

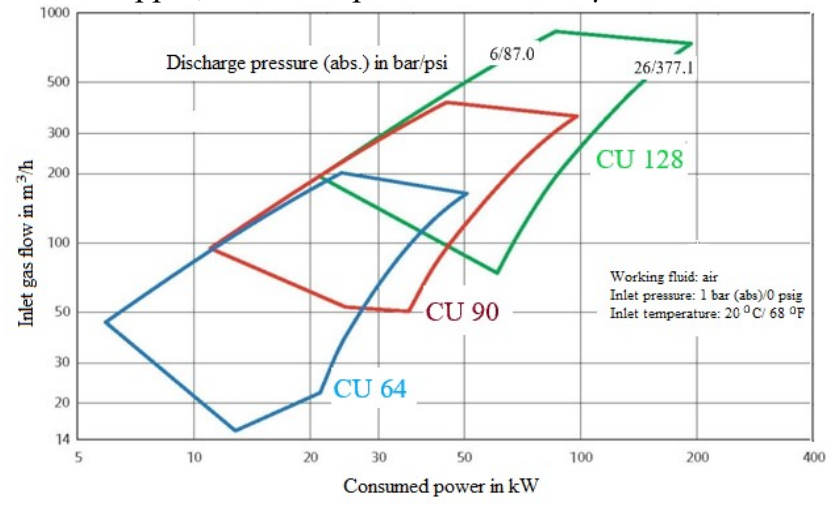

Fig. 2. Characteristics of the compressor units, showing CU 128 compressor used

The operation parameters of the installation (Figure 3a) were analysed, which conducted to the observation of the need for a buffer tank (Figure $3 \mathrm{~b}$ ) between the compressor and the autoclave, in order to ensure the air consumption during operation in the pressure- 
temperature curve of the autoclave. The buffer tank was sized, appreciating the exchange of air masses that takes place in the bearing stage, establishing an optimum volume of $3 \mathrm{~m}^{3}$.

a)
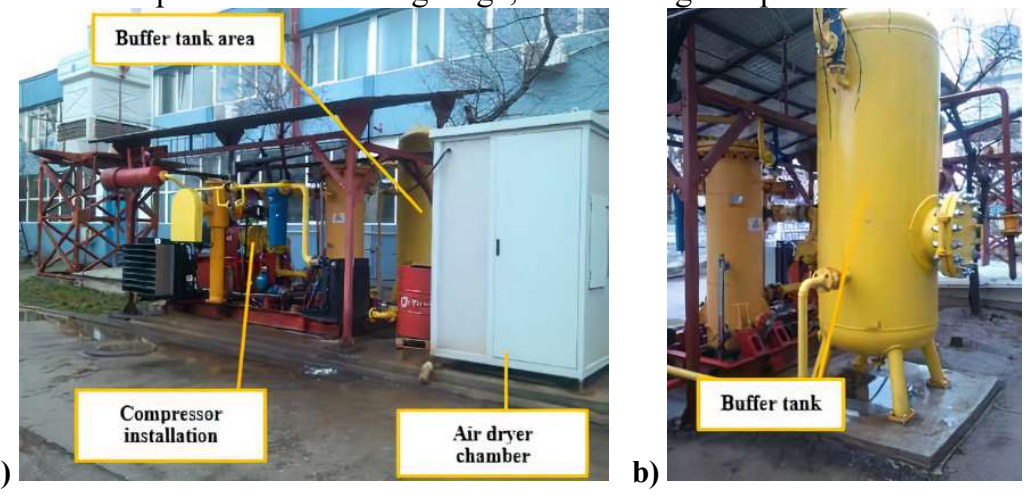

Fig. 3. a) Outdoor autoclave assembly with compressor, b) Buffer tank

The buffer tank has the role of limiting the starts/stops of the induction motor. Due to overcurrent of very high amperage occurring at the start-up of electric induction motors, the time required in order to accelerate loads with high inertia gives birth to sudden temperature rises. If the time interval between successive start-ups is very short, the motor's windings may overheat, which can cause insulation damage and thus reducing lifetime. Temperature is also influenced by the motor's capacity to dissipate heat. The useful lifetime of the motor depends on the life of the winding insulation, being affected by various factors, such as moisture, vibration, corrosion etc. Among all factors affecting electric motor lifetime, the most critical is the temperature of the insulation materials [7].

\section{Tests computations}

A maximum buffer tank volume of $3 \mathrm{~m}^{3}$ was considered, due to placement constraints. The calculations [8] use the experimental data obtained during the commissioning tests with the compressor [9-11] without buffer tank. The tests were performed in the following conditions:

(1) Air pressure $=7 \mathrm{bar}$, working temperature $=140{ }^{\circ} \mathrm{C}$.

(2) Air pressure $=15$ bar, working temperature $=200^{\circ} \mathrm{C}$.

(3) Air pressure $=18$ bar, working temperature $=400{ }^{\circ} \mathrm{C}$.

The tests were conducted at relative pressure values, which were converted to absolute values. If not specified, the pressure unit [bar] generally means relative pressure [bar (rel)]. The input data is: autoclave volume: $\mathrm{V}_{\mathrm{A}}=12.5 \mathrm{~m}^{3}$; buffer tank volume: $\mathrm{V}_{\mathrm{BT}}=3 \mathrm{~m}^{3}$; compressor separator vessel volume: $\mathrm{V}_{\mathrm{C}}=0.5 \mathrm{~m}^{3}$; compressor discharge air temperature: $\mathrm{T}_{\mathrm{C}}=50^{\circ} \mathrm{C}$. The buffer tank is dimensioned for 24 bar and $50{ }^{\circ} \mathrm{C}$, considering the operating limits of the screw compressor. Three operation stages were considered:

A) Steady state at constant pressure and constant temperature.

B) Constant pressure and air cooling.

C) Evacuation of the air with decreasing of the pressure and temperature down to the atmospheric conditions. The autoclave filling time at required pressure is not considered.

\subsection{First set of tests $\left(7 \mathrm{bar}, 140^{\circ} \mathrm{C}\right)$}

\section{A) Steady state}


During the steady state period, there is an emptying-filling activity with pressure variations of $-0.02 /+0.01$ bar at 1.5 minutes. The air mass required to fill up the autoclave is the difference between the air mass occupied at the pressure of +0.01 bar and the mass occupied at the pressure of -0.02 bar. An adiabatic process is considered, with the following initial values: $P=7$ bar (rel), $T=413.16 \mathrm{~K}, R=287.14 \mathrm{~J} / \mathrm{KgK}$. Two air states are assumed, at the absolute pressures of 8.01 bar (abs) and 7.98 bar (abs) respectively. At $P_{n}$ pressure, the temperature $T_{n}$ is calculated as:

$$
T_{n}=T \cdot\left(\frac{P_{n}}{P}\right)^{\frac{k-1}{k}}
$$

The corresponding air mass is:

$$
M_{n}=\frac{P_{n} \cdot V_{A}}{R \cdot T_{n}}
$$

Table 1. Data calculated for the two air states

\begin{tabular}{|c|c|c|c|}
\hline State & $\boldsymbol{P}_{\boldsymbol{n}}\left[{ }^{\circ} \mathbf{C}\right]$ & $\boldsymbol{T}_{\boldsymbol{n}}\left[{ }^{\circ} \mathbf{C}\right]$ & $\boldsymbol{M}_{\boldsymbol{n}}[\mathbf{k g}]$ \\
\hline $1^{\text {st }}$ state & $P_{l}=8.01$ bar (abs) & $T_{1}=413.3 \mathrm{~K}$ & $M_{1}=84.371$ \\
\hline $2^{\text {nd }}$ state & $P_{2}=7.98$ bar (abs) & $T_{2}=412.9 \mathrm{~K}$ & $M_{2}=84.145$ \\
\hline
\end{tabular}

The air mass lost within the autoclave is $M_{\text {loss }}=M_{1}-M_{2}=0.226 \mathrm{~kg}$. This amount of air is required for during the exhaust-intake cycles, for a period of time of $t_{c}=1.5 \mathrm{~min}$. The calculations for the buffer tank are similar, with the observation that the pressure decreases from 24 bar (rel), namely 25 bar (abs), to a pressure of $7+3$ bar or $8+3$ bar (abs). A pressure of 3 bar is required, higher than the pressure in the autoclave. The temperature $(T$ $=50{ }^{\circ} \mathrm{C}$ ) decreases adiabatically. The initial conditions are: $P_{B 1}=25$ bar (abs); $P_{B 2}=11$ bar (abs); $T_{B I}=323.16 \mathrm{~K}$. The mass and temperature in the buffer tank, states 1 and 2 are calculated with the following relations:

$$
M_{B T_{n}}=\frac{P_{n} \cdot V_{B T}}{R \cdot T_{n}}
$$

From the equation (1), we have $T_{2}=T_{1} \cdot\left(P_{2} / P_{1}\right)^{\frac{k-1}{k}}=255.592 \mathrm{~K}$. Obtaining the air masses from equation (3) $M_{B T_{1}}=80.829 \mathrm{~kg}$ and $M_{B T_{2}}=44.966 \mathrm{~kg}$, the mass loss in the buffer tank is hence $M_{B T}=M B_{T 1}-M B_{T 2}=35.862 \mathrm{~kg}$. The buffer tank loses this mass during a pressure decrease of 14 bar, from 25 bar (abs) to 11 bar (abs). The number of cycles, $N_{c} \cong$ 159 , for autoclave operation with buffer tank, results from equation (4):

$$
N_{c}=\frac{M_{B T}}{M_{\text {loss }}}
$$

The maximum stationary time $t_{s t}$ of the autoclave is calculated with relation (5) below. If this time is longer than the calculated value, a new start-up of the compressor is required, for compensating the air mass lost by the autoclave.

$$
t_{s t}=N_{c} \cdot t_{c}=3.97 \mathrm{~h}
$$

\section{B) Constant pressure, air cooling at 7 bar}

At the end of the steady state period, the air inside the autoclave is beginning to cool down, maintaining a constant pressure. Thus, at a constant pressure of 7 bar, the air mass corresponding to the temperature from Table 2 (showing 10 selected sample values) was calculated, as well as the differences between two successive temperatures. 
Table 2. Temperature values at constant pressure of 7 bar

\begin{tabular}{|c|c|c|c|c|c|c|c|c|c|c|}
\hline $\boldsymbol{i}=\mathbf{1 . . 5 5}$ & 1 & 6 & 12 & 18 & 24 & 30 & 36 & 42 & 48 & 55 \\
\hline $\boldsymbol{T}\left[{ }^{\circ} \mathbf{C}\right]$ & 140.3 & 131.6 & 120.2 & 108.9 & 96.8 & 85 & 73.6 & 62 & 50.9 & 39.8 \\
\hline
\end{tabular}

Due to the air cooling, it is necessary to supply an air mass in the buffer tank, in order to maintain a constant pressure inside the autoclave. The variation of the autoclave mass, $M_{A i}$, with $i=1 . .55$, is given by the equation below.

$$
M_{A i}=\frac{P_{1 i} \cdot V_{1}}{R \cdot T_{1 i}}
$$

From the iterations, the total mass loss of the autoclave is $M_{\text {loss }}=M_{A}=M_{A 55}-M_{A 1}=$ $27.05 \mathrm{~kg}$, which should be provided by the buffer tank. The mass lost by the buffer tank for this variation is $M_{B T}=35.862 \mathrm{~kg}$. We conclude that a $3 \mathrm{~m}^{3}$ buffer tank is sufficient for ensuring the installation's operation throughout the cooling cycle, $M_{B T}>M_{A}$. In this scenario $\left(7\right.$ bar, $\left.140{ }^{\circ} \mathrm{C}\right)$, mass lost can be supplied by buffer tank, without restarting the compressor.

\section{C) $\underline{\text { Air evacuation }}$}

At the end of duty cycle, the air is evacuated from the autoclave, as it cools down to a temperature of $23{ }^{\circ} \mathrm{C}$. The values for pressure, temperature and successive differences of the mass are presented in Table 3.

Table 3. Cooling process at the end of duty cycle

\begin{tabular}{|l|c|c|c|c|c|c|c|c|c|c|}
\hline $\boldsymbol{i}=1 . .37$ & 1 & 4 & 8 & 12 & 16 & 20 & 24 & 28 & 32 & 37 \\
\hline $\boldsymbol{T}\left[{ }^{\circ} \mathbf{C}\right]$ & 39.8 & 37.9 & 35.6 & 33.1 & 30.5 & 29.7 & 27.5 & 25.5 & 24.3 & 23.3 \\
\hline $\boldsymbol{P}[\mathbf{b a r}]$ & 7 & 6.3 & 5.4 & 4.5 & 3.6 & 2.6 & 1.7 & 0.9 & 0.4 & 0 \\
\hline $\boldsymbol{M}_{\boldsymbol{A} i}[\mathbf{N D}]$ & 1.18 & 2.639 & 2.621 & 2.695 & 4.22 & 2.826 & 2.811 & 2.89 & 1.438 & 0 \\
\hline
\end{tabular}

The calculation with (6) show that the mass differences discharged at successive temperatures are positive, see the table 3 , and therefore we can conclude that during the period of autoclaved air evacuation and temperature drop, external air mass supply is not required, and compressor can be stopped.

\subsection{Second set of tests $\left(15 \mathrm{bar}, 200^{\circ} \mathrm{C}\right)$}

\section{A) Steady state}

Similarly to the first set of tests, an adiabatic transformation with the same emptying-filling pressure variations was considered, with the following initial values corresponding to a temperature of $200{ }^{\circ} \mathrm{C}: P=15 \mathrm{bar}, T=473.16 \mathrm{~K}, R=287.14 \mathrm{~J} / \mathrm{KgK}$. Two air states are assumed, at the absolute pressures $P_{1}=16.01$ bar (abs) and $P_{2}=15.98$ bar (abs) respectively. Using equations (1) and (2), the autoclave air mass is calculated to be $M_{\text {loss }}=$ $0.197 \mathrm{~kg}$. Relying on equations (1) and (3), the air mass loss in the buffer tank is $M_{B T}=$ $14.388 \mathrm{~kg}$, for a pressure drop of $6 \mathrm{bar}$, from $25 \mathrm{bar}$ (abs) to 19 bar (abs). The number of resulting operation cycles with buffer tank is calculated with relation (4) to be $N_{c} \cong 73$. A maximum stationary time $t_{s t}=1.8 \mathrm{~h}$ is calculated with relation (5). As in the first case, if this time is longer than this value, a new compressor start-up is required, for compensating the air mass lost by the autoclave.

\section{B) Constant pressure, air cooling at 15 bar}


At the end of the steady state period, the air inside the autoclave is beginning to cool down, maintaining a constant pressure of 15 bar. The air masses corresponding to the temperatures in Table 4 were calculated, as well as the differences between two successive temperatures.

Table 4. Temperature values at constant pressure of 15 bar

\begin{tabular}{|l|c|c|c|c|c|c|c|c|c|c|}
\hline $\boldsymbol{i}=\mathbf{1 . . 3 6}$ & 1 & 4 & 8 & 12 & 16 & 20 & 24 & 28 & 32 & 36 \\
\hline $\boldsymbol{T}\left[{ }^{\circ} \mathbf{C}\right]$ & 200 & 186.4 & 166 & 146.5 & 124.2 & 105.6 & 83.5 & 65.5 & 55.1 & 43.8 \\
\hline
\end{tabular}

Applying relation (6) to iterations, the total air mass loss to be provided by the buffer tank is $M_{\text {loss }}=M_{A}=M_{A 36}-M_{A l}=72.547 \mathrm{~kg}$. The mass loss in the buffer tank is $M_{B T}=$ $14.388 \mathrm{~kg}$.

Hence, a $3 \mathrm{~m}^{3}$ buffer tank alone cannot sustain the operation of the autoclave for the temperature drop during the entire cooling cycle, $M_{B T}<M_{A}$. This means that in this scenario $\left(15\right.$ bar, $200{ }^{\circ} \mathrm{C}$ ), the compressor start-up would be required during the autoclave duty cycle.

\section{C) Air evacuation}

At the end of duty cycle, the air is evacuated from the autoclave, simultaneously with its cooling, down $21.1^{\circ} \mathrm{C}$. The values in Table 5 are given for 10 iteration samples.

Table 5. Cooling process at the end of duty cycle

\begin{tabular}{|l|c|c|c|c|c|c|c|c|c|c|}
\hline $\boldsymbol{i}=1 . .36$ & 1 & 4 & 8 & 12 & 16 & 20 & 24 & 28 & 32 & 36 \\
\hline $\boldsymbol{T}\left[{ }^{\circ} \mathbf{C}\right]$ & 43.8 & 37.9 & 33.7 & 29.8 & 26.8 & 24.9 & 23.7 & 23.2 & 21.7 & 21.1 \\
\hline $\boldsymbol{P}[\mathbf{b a r}]$ & 15 & 13 & 10 & 7 & 4.4 & 2.7 & 1.5 & 0.8 & 0.3 & 0 \\
\hline $\boldsymbol{M}_{\boldsymbol{A} \boldsymbol{i}}[\mathbf{N D}]$ & 2.129 & 9.076 & 10.829 & 9.746 & 7.114 & 4.332 & 2.91 & 2.922 & 1.458 & 0.015 \\
\hline
\end{tabular}

The computations with (6) show that the mass differences discharged at successive temperatures are positive see the table 5, which leads to the conclusion that during the period of autoclaved air evacuation and temperature decrease, it is no longer necessary to supply external air mass, the compressor being stopped (see subsequent figure 6 and figure 7).

\subsection{Third set of tests $\left(18 \mathrm{bar}, 400^{\circ} \mathrm{C}\right)$}

\section{A) Steady state}

The same calculation method and relations as described in the first two sets of tests were used for an adiabatic transformation, with the following initial values: $P=18$ bar (rel), $T=$ $673.16 \mathrm{~K}, R=287.14 \mathrm{~J} / \mathrm{KgK}$. Two air states are assumed, at the absolute pressures $P_{1}=$ 19.01 bar (abs) and $P_{2}=18.98$ bar (abs) respectively. Relying on equations $(1) \div(3)$, we calculated the air mass loss for autoclave $M_{\text {loss }}=0.139 \mathrm{~kg}$, and for buffer tank $M_{B T}=7.053$ $\mathrm{kg}$, during a pressure drop of 3 bar, from 25 bar (abs) to 19 bar (abs). The number of resulting cycles for autoclave operation with buffer tank is calculated with relation (4) to be $N_{c} \cong 51$. Maximum stationary time is obtained with relation (5), to be $t_{s t}=1.27 \mathrm{~h}$. If this time is exceeded, compressor start-up is required.

\section{B) Constant pressure, air cooling at 18 bar}

The data regarding the temperature decrease is summarised in Table 6. The air inside the autoclave cools, keeping the pressure constant at 18 bar. The air mass corresponding to each temperature, and the differences between two successive temperatures have been calculated. 
Table 6. Temperature values at constant pressure of 18 bar

\begin{tabular}{|l|c|c|c|c|c|c|c|c|c|c|c|}
\hline $\boldsymbol{i}=\mathbf{1 . . 8 2}$ & 1 & 8 & 16 & 24 & 32 & 40 & 48 & 56 & 64 & 72 & 82 \\
\hline $\boldsymbol{T}\left[{ }^{\circ} \mathbf{C}\right]$ & 400 & 368.2 & 327 & 286.8 & 246.8 & 207.7 & 167.6 & 127.6 & 86.8 & 59.5 & 38.8 \\
\hline
\end{tabular}

From the iterations, using relation (3), the total mass loss which has to be compensated by the buffer tank is $M_{\text {loss }}=M_{A}=M_{A 82}-M_{A l}=142.271 \mathrm{~kg}$. The mass lost by the buffer tank is hence $M_{B T}=7.053 \mathrm{Kg}$. Therefore, a $3 \mathrm{~m}^{3}$ buffer tank alone cannot sustain the operation of the autoclave for the temperature drop during the entire cooling cycle, $M_{B T}<M_{A}$. At cycle $N_{C}=9$, the air mass loss is $7.188 \mathrm{~kg}$, and at $N_{C}=8$, it is $6.092 \mathrm{~kg}$. The conclusion is that the buffer tank alone ensures the proper operation for only 9 cycles of 30 seconds each, namely for $4.5 \mathrm{~min}$. In this scenario $\left(18 \mathrm{bar}, 400{ }^{\circ} \mathrm{C}\right)$, the compressor will function continuously during the whole autoclave duty cycle.

\section{C) Air evacuation}

At the end of duty cycle, the air is evacuated from the autoclave and cools down to $23.7^{\circ} \mathrm{C}$. The pressure, temperature and successive mass differences are summarized in Table 7.

Table 7. Cooling process at the end of duty cycle

\begin{tabular}{|l|c|c|c|c|c|c|c|c|c|c|}
\hline $\boldsymbol{i}=1 . .37$ & 1 & 4 & 8 & 12 & 16 & 20 & 24 & 28 & 32 & 38 \\
\hline $\boldsymbol{T}\left[{ }^{\circ} \mathbf{C}\right]$ & 38.8 & 35.5 & 33 & 30.7 & 28.9 & 27.8 & 26.8 & 26.1 & 25.5 & 23.7 \\
\hline $\boldsymbol{P}[\mathbf{b a r}]$ & 18 & 15.8 & 13.1 & 10.5 & 7.8 & 5.2 & 3 & 1.6 & 0.5 & 0 \\
\hline $\boldsymbol{M}_{\boldsymbol{A} \boldsymbol{i}}[\mathbf{N D}]$ & 9.772 & 9.357 & 8.155 & 9.774 & 9.934 & 10.073 & 7.24 & 4.342 & 2.907 & 0.025 \\
\hline
\end{tabular}

The computations show that the mass differences discharged at successive temperatures are positive, which means that during air evacuation, the compressor can be stopped.

Hereinafter, we present the graphical representations of the analytical data obtained. Figure 4 shows the variations of the evacuated air mass and the temperature for constant pressures discussed ( 7 bar, 15 bar and 18 bar respectively). A cycle duration is $1.5 \mathrm{~min}$.

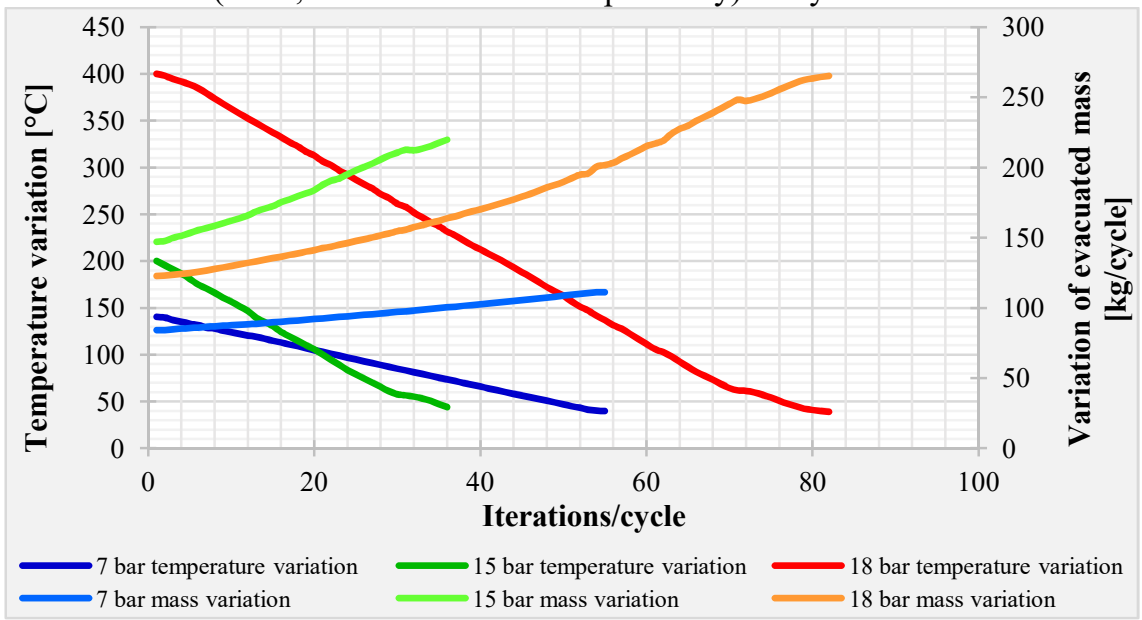

Fig. 4. Evacuated air mass and temperature at constant pressures

Figure 5 shows the computations results for the variation of negative air mass between two successive temperatures at constant pressure, during air cooling process. 


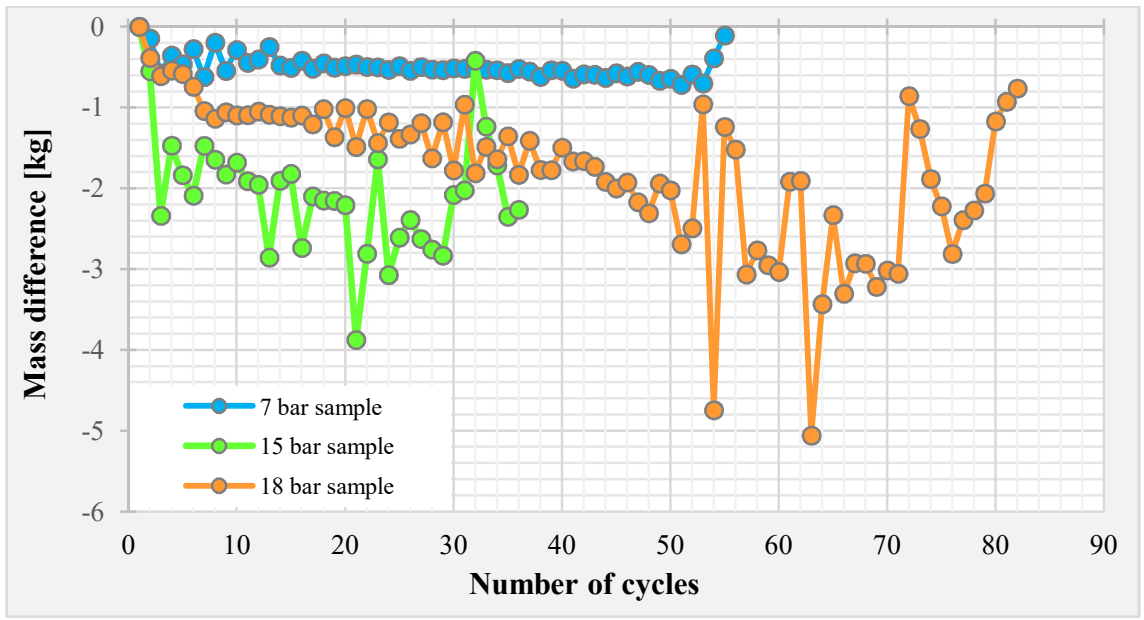

Fig. 5. Negative mass variation between two successive temperatures

Figure 6 shows the variation of the evacuated mass and temperature at the end of autoclave duty cycle.

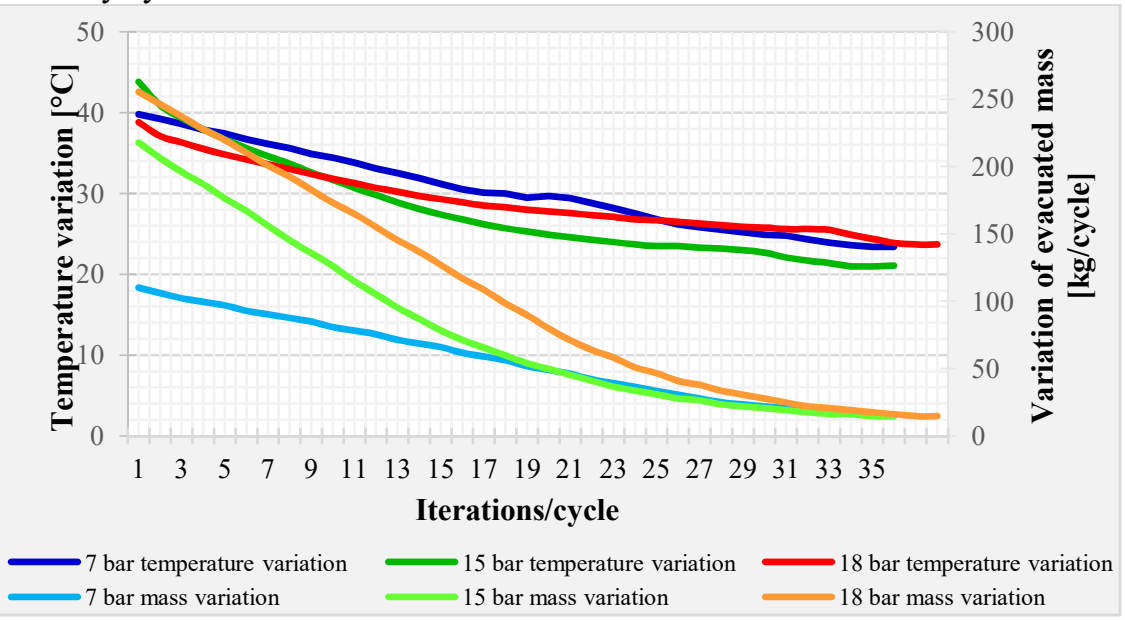

Fig. 6. Variation of the evacuated mass and temperature at the end of duty cycle

Figure 7 shows the computations results for the variation of positive air mass between two successive temperatures at constant pressure, during the air cooling process. 


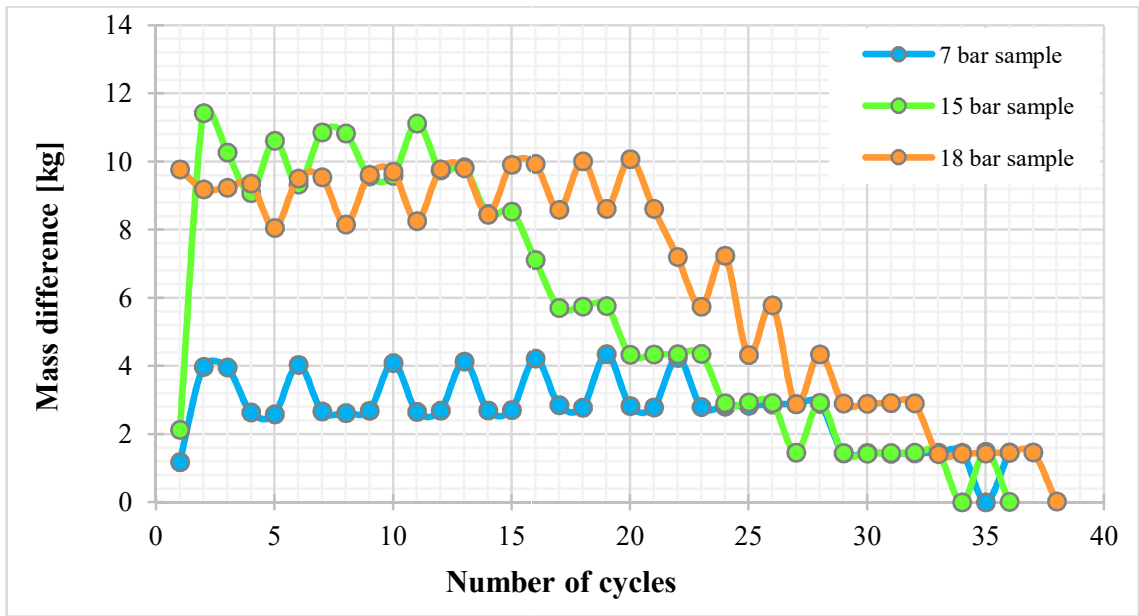

Fig. 7. Positive variation in mass between two successive temperatures at autoclave completion

\section{Automation control system}

The automation system has the purpose of driving, controlling and monitoring of an air compression equipment up to 24 bar (gauge). The compressed air is stored in a buffer tank and is used for supplying air mass to the autoclave. Depending on this one's consumption, the stored air volume decreases, being compensated by using the electro-compressor. If the pressure is within normal limits, the compressor enters in a standby mode, for saving electrical energy consumption. It only starts automatically when the pressure in the buffer tank falls below the limit value set in the PLC (Programmable Logic Controller) software.

Three architectures were considered for the implementation of the automation system, discussed hereinafter. For versatility, the software implemented in the PLC was realised to allow it to be extended for several other applications and functioning regimes.

\section{A) Structure with PLC and local data acquisition}

The local DAQ (data acquisition) is realised via connection cables for measuring the parameters of interest, from transducers to the interfaces of the PLC. The PLC is located remotely, in a control box situated in the control room. This supposes collecting the transducers' signal conductors in a junction box with terminal blocks, and gathering these ones in a joint cable to the electrical control box. Usually, the maximum distance between the transducer and PLC interface is between $10 \mathrm{~m}$ and $100 \mathrm{~m}$. In case of exceeding the specified distance, the accuracy of the signal cannot be guaranteed. The advantages of this solution are: compact PLC, all data is in proximity, safe signal transmission. The main disadvantage is presented by the long cable comprising several conductors. The conductors have to be twisted-paired and shielded separately.

\section{B) Structure with PLC and distributed data acquisition}

The distributed DAQ is realised using modules mounted near the transducers. Thus, the data in the CPU (central processing unit) is obtained via communication between acquisition system near the measured process and PLC. The advantages are shortening connection length between transducers and DAQ module, and connection between local DAQ and PLC with communication cable with few conductors. However, a thermostatic enclosure is required for the acquisition equipment, and DAQ has to be doubled for safety systems. 


\section{C) PLC control with Panel PC and HMI software}

Within the purchased Panel PC, we installed "Advanced HMI" which runs under "Microsoft Visual Studio Community" and "Microsoft .NET Framework version 4.8". In this panel PC, LabView can also be installed, for the monitoring and recording application. AdvancedHMI is an open-source software used for creating HMI (Human-Machine Interface) applications that communicate with the PLC or with the device. The result is a very fast and effective application. By using a Modbus TCP library, the visualisation can be realised in network for monitoring the compressor on the intranet or internet (using VPN for increased data safety).

For the practical implementation of the automation system (Figure 8), we chose an architecture with PLC and distributed DAQ, local commands and DAQ, and HMI configured in the Panel PC, within the front panel of the control box.
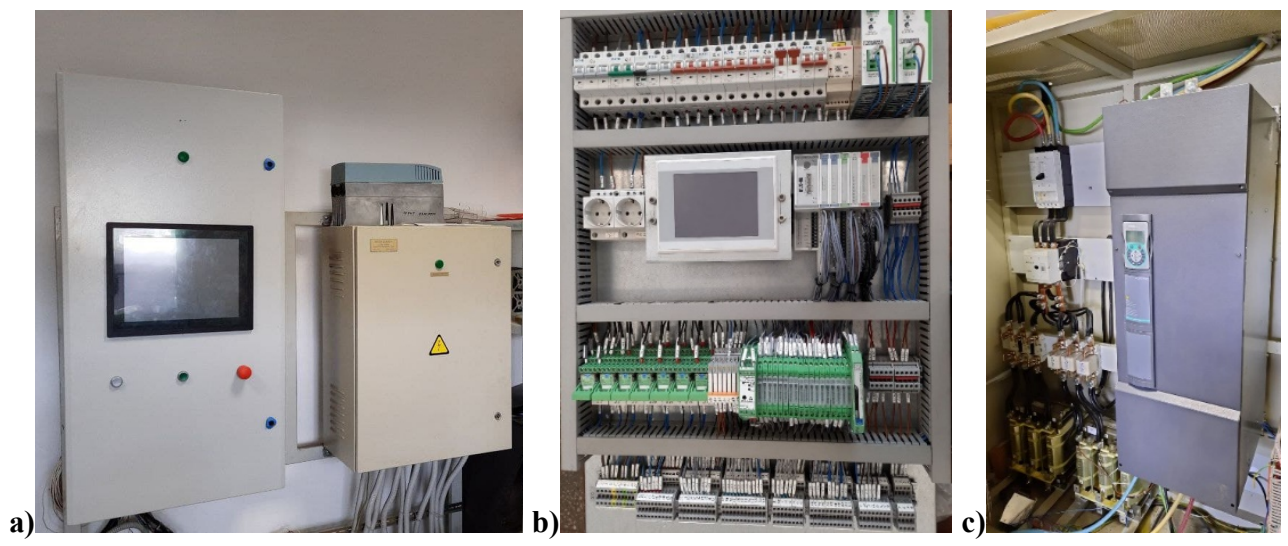

Fig. 8. Automation system: a) local automation cabinets; b) equipped counter-panel; c) drives cabinet with frequency converter, contactors and fuses

The digital signals are acquired in two ways: directly, if produced by their own power supply in contact with internal relay in the control room, or through a galvanic separator if the signals are generated in the field, using the PLC's power supply.

\section{Conclusions}

The paper presents the computations made for choosing the optimum operation parameters of an autoclave for developing aeronautical composite materials. Prolonging the lifetime of its electro-compressor and driving motor is realised by reducing the number of start-ups and shutdowns, and also avoiding these ones' continuous operation over the entire autoclave duty cycle. The results show that, for reducing the electricity demands and prolonging equipment lifetime, the optimum operation regime occurs for autoclave air pressure of 7 bar, at $140{ }^{\circ} \mathrm{C}$ temperature. Due to the fact that the autoclave requires a flow rate of $0.13 \mathrm{~kg}$ per second, a higher-pressure compressor (40 bar) and a higher volume buffer tank would be required for ensuring the air flow at 18 bar and $400{ }^{\circ} \mathrm{C}$. However, the need for higher pressure and temperature occurs occasionally, only for certain special composites. In the main working range, the buffer tank suffices along with the present 20 bar compressor.

This research was funded within the project "Development of Research infrastructure for EMerging Advanced composite materials dedicated to innovative STator ogv technologies for aircrafts Engine noise Reduction", code MySMIS 132263, acronym REMASTER, contract no. 12/1.1.3H/28.04.2020. 


\section{References}

1. V. Karbhari, Fabrication, quality and service-life issues for composites in civil engineering. Durability of Composites for Civil Structural Applications. pp. 13-30 (2007). DOI: 10.1533/9781845693565.1.13.

2. M. Condruz, C. Puscasu, L. Voicu, I. Vintila, A. Paraschiv and D. Mirea, "Fiber Reinforced Composite Materials for Proton Radiation Shielding", Materiale Plastice 55, 1 (2018), pp. 5-8. DOI: 10.37358/mp.18.1.4952.

3. G. Seon, Y. Nikishkov, A. Makeev and L. Ferguson, "Towards a digital twin for mitigating void formation during debulking of autoclave composite parts", Eng Fract Mech. 225, p. 106792 (2020). DOI: 10.1016/j.engfracmech.2019.106792.

4. A. Fomin, P. Khavanov, M. Kozhukhova, "Autoclave Composites Containing Ferriferous Industrial By-Products", Materials Science Forum 945, pp. 1030-1035 (2019). DOI: 10.4028/www.scientific.net/msf.945.1030.

5. "Oil Injected Airends | GHH Rand", ghhrand, 2021, https://oemsolutions.ingersollrand.com/en-us/products/integrated-compression/oil-injectedairends.

6. "COMOTI - Romanian Research and Development Institute for Gas Turbines", Comoti.ro, 2021, http://www.comoti.ro/en/Compresoare-cu-surub.htm.

7. "Practical tips on how not to burnout an electric motor", EEP - Electrical Engineering Portal, 2021, https://electrical-engineering-portal.com/burnout-electric-motor.

8. S. Neacșu, Termotehnică și Mașini Termice (Bucureşti: Printech, 2009). ISBN: 978606-521-375-3.

9. C. Eparu, S. Neacșu, A. Neacșa, A. Prundurel, "The comparative thermodynamic analysis of compressor's energetic performance", Mathematical Modelling of Engineering Problems 6, 1 (2019), pp. 152-155. DOI: 10.18280/mmep.060120.

10. N. Stosic, I. Smith, A. Kovačević, Screw Compressors Mathematical Modeling and Performace Calculation (Berlin: Springer, 2005). ISBN 978-3-540-26228-2.

11. N. Seshaiah, R. Sahoo, S. Sarangi, "Theoretical and experimental studies on oil injected twin-screw air compressor when compressing different light and heavy gases", Appl Therm Eng. 30, 4 (2009), pp. 327-339. DOI: 10.1016/j.applthermaleng.2009.09.010. 